\title{
A Case Report: Effect of Korean Medicine Including Distilled Form of Bosaeng-tang Gagambang on Moderate to Severe Hyperemesis Gravidarum.
}

\author{
Hae-Won Kim ${ }^{1,2}$, Seon-Eun Baek², Dong-Youl Yoo ${ }^{1}$, Jeong-Eun Yoo ${ }^{1,2^{*}}$ \\ ${ }^{1}$ Dept. of Korean Medicine Obstetrics \& Gynecology, College of Korean Medicine, Daejeon University. \# 62 , \\ Daehak-ro, Dong-gu, Daejeon. 34520, Republic of Korea. \\ ${ }^{2}$ Dept. of Korean Medicine Obstetrics \& Gynecology, Daejeon Korean Medicine Hospital of Dae-jeon \\ University. 75 Daeduk-daero 176 beon-gil, Seo-gu, Daejeon. 35235, Republic of Korea
}

\begin{abstract}
Objectives: Hyperemesis gravidarum (HG) is defined as severe nausea and vomiting during pregnancy (NVP) with weight loss, ketonuria, and electrolyte imbalance. Many NVP or HG patients get hard to take herbal medicine since the smell and taste of it. Therefore, the distilled herbal medicines are often used in clinical practice. A 32-year-old, 14-week pregnant female was admitted for 3 weeks at a Korean medicine hospital. She was experiencing HG accompanied by $19.61 \%(10 \mathrm{~kg})$ weight loss, ketonuria, and electrolyte imbalance. The patient received Bosaeng-tang gagambang in its distilled form, acupuncture, electro-acupuncture, sticker needles, cupping, moxibustion, and hydration during admission. The severity and frequency of NVP, weight loss, and ketonuria significantly improved without any side effects. Before the therapy, she admitted to two obstetrics and gynecology hospitals, 1 week each, with no improvement. This case presents the therapeutic potential of Korean medicine including herbal medicine in its diluted form for HG and NVP.
\end{abstract}

$\overline{\text { Key Words }}$ : Case Report, Hyperemesis Gravidarum (HG), Traditional Korean Medicine (TKM), Distilled form of herbal medicine, Bosaeng-tang Gagambang

\section{Introduction}

About $70-80 \%$ of pregnant women experience nausea and vomiting of pregnancy (NVP), also known as 'morning sickness'. Most of NVP occurs around week 5 and disappears around week 12 of pregnancy. ${ }^{1)}$ While this causes discomfort to patients, weight is not affected and symptoms are not severe, so no special treatment is required. ${ }^{2)}$ However, for about 0.5 to $2.0 \%$ of pregnant women, NVP is very severe." Severe NVP that is accompanied by dehydration, electrolyte imbalance, ketonuria, and weight loss of $5 \%$ or more is diagnosed as hyperemesis gravidarum $(\mathrm{HG}) .{ }^{4)}$

Even though the incidence of $\mathrm{HG}$ is low, it causes the patient many problems. If $\mathrm{HG}$ continues for an extended period, it can cause damage to the central nervous system, liver, and kidneys of pregnant women and affect the health

\footnotetext{
- Received : 5 October 2020

- Revised : 24 November 2020

- Accepted : 25 November 2020

- Correspondence to : Jeong-Eun Yoo

Dept. of Korean Medicine Obstetrics \& Gynecology Daejeon Korean Medicine Hospital of Dae-jeon University

75 Daeduk-daero 176 beon-gil, Seo-gu, Daejeon. 35235, Republic of Korea

Tel : +82-42-470-9139; Fax : +82-42-470-9009, E-mail: jeyoo@dju.ac.kr
} 
of the fetus. In addition, various social and mental problems can accompany $\mathrm{HG}^{5}$, and some pregnant women decide to end their pregnancy because of it. ${ }^{6)}$ Therefore, appropriate treatment and hospitalization is required to care for $\mathrm{HG}^{5}{ }^{5}$

Various factors linked to NVP have been widely studied: hormones; placental serum markers; immune, infection, and anatomical factors; vitamin deficiencies; and psychological causes, among others. However, the etiology and pathogenesis of NVP or HG are still unclear. ${ }^{7)}$ Therefore, conventional therapy strategies are limited to adjuvant treatments such as hydration and vitamins for symptom relief or the prevention of complications. In severe cases, such as for $\mathrm{HG}$, anti-emetic medications may be used after considering the risks and benefits. ${ }^{8)}$

This study reports a case of an HG patient who improved after Korean medicine with distilled herbal medicine. Before she came to the Korean medicine hospital, she received conventional inpatient treatment twice, both of which included hydration and anti-emetic medications without effect. This case report shows that Korean Medicine could be a safe treatment option without adverse effects for moderate to severe $\mathrm{HG}$ that lasts until the second trimester of pregnancy and that does not respond to anti-emetics.

Many NVP or HG patients get hard to take herbal medicine since the smell and taste of it. In clinical practice, distilled herbal medicines are often used for NVP or HG because patients with NVP or HG frequently complain nauseate with herbal medicines' smell and taste. However, no study has investigated the effect and safety of distilled herbal medicine on $\mathrm{HG}$ patient. This study shows Korean medicine treatment including distilled Bosaeng-tang gagambang could be the effective and safe treatment option for $\mathrm{HG}$, which does not respond to conventional inpatient treatment.

\section{Case Report}

\section{Patient characteristics and medical history}

A 32-year-old woman, who was 14 weeks pregnant, came to our Korean medicine hospital with nausea, vomiting, and heartburn. The patient had had two full-term births, both with NVP but not HG. She had no other past history or family history.

On admission, she was experiencing severe nausea, which persisted throughout the day and was unrelated to meals. Vomiting occurred on average 4 to 5 times a day. Heartburn, which was caused by the frequent vomiting, worsened when in a lying position. She had infrequent, watery stools with low output once every 7 days. Before admission, her last defecation had been 7 days previous. The patient had almost no oral intake, so there was no discomfort caused by constipation.

These symptoms started at week 6 of pregnancy, in mid-December 2018. She reported that after mid-January 2019, when she was 10 weeks pregnant, the NVP became more severe, making oral intake difficult. The patient started drinking about a half bottle of fruit juice or an ionic beverage once per day, during about 4 weeks before visiting the Korean medicine hospital.

At the time of her first visit, the patient's body weight was $41 \mathrm{~kg}$. Compared to her pre-pregnancy weight, she had experienced 


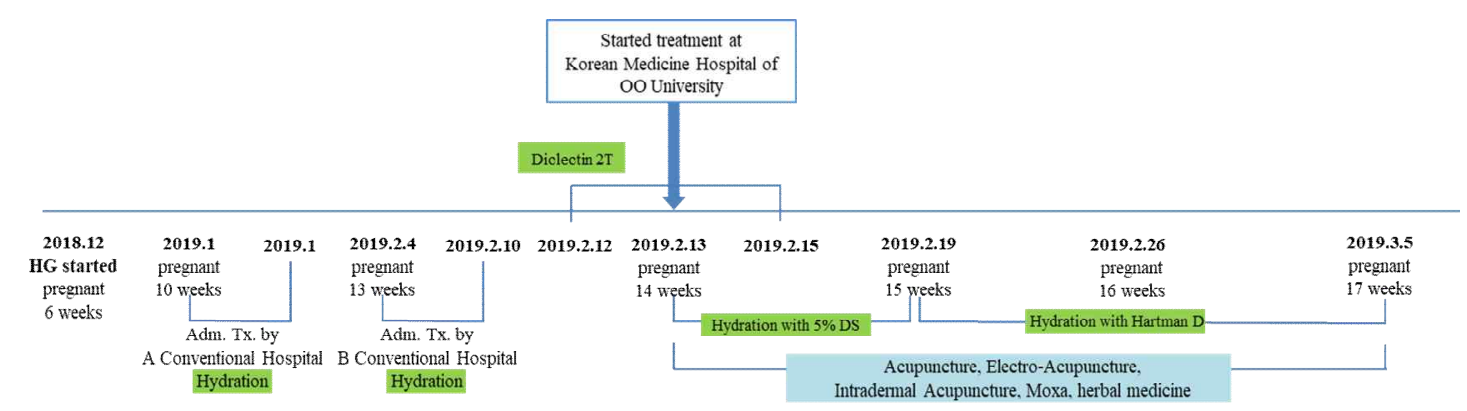

Fig. 1. Patient's HG treatment timeline

weight loss of about 19.61\% (10 kg). Walking on her own was difficult due to the deterioration of her general condition, so she came to the hospital in a wheelchair.

The patient had received inpatient treatment at two different conventional hospitals, once when she was 10 weeks pregnant in mid-January 2019 , and the other at 13 weeks of pregnancy on February 4, 2019. On the day before she visited the Korean medicine hospital, she took 2 tablets of combined doxyramine and pyridoxine (product name Diclectin, delayed release tablet) after dinner, prescribed by the conventional hospital. Due to the lack of improvement from conventional treatments, she visited the Korean medicine hospital on February 13, 2019 (Fig. 1).

Before the study, the patient signed an agreement to have her personal information included, and the study was approved by the institutional review board at $\mathrm{OO}$ Korean medicine hospital of $\mathrm{OO}$ university (deliberation number: DJDSKH-20-E-07-1).

\section{Diagnosis and outcome evaluation}

Electrolyte imbalances were detected on her blood test and ketone, urobilinogen, and bilirubin were detected on the urinalysis taken shortly after admission. The serum panel was also checked to rule out chronic hepatitis $\mathrm{C}$, which is associated with a high incidence of nausea, ${ }^{9)}$ and it was within normal range. Her complete blood count, liver function tests and vital signs such as blood pressure, heart rate, respiration rate, body temperature, and blood glucose were within normal range. $\mathrm{HG}$ is diagnosed because she had NVP accompanied by weight loss ( $>5 \%$ of weight), dehydration, ketonuria, and electrolyte imblances.

The Korean medicine pattern-diagnosis was performed based on the shape of body type, ordinary symptoms, pulse diagnosis, and tongue diagnosis. This patient generally had poor digestive function. A weak pulse and pale tongue with a thick white coating were evident during the pulse and tongue diagnosis. The patient's pathological state was classified as 'weakness of the spleen and stomach' in Korean medicine theory.

For this case, the severity of $\mathrm{HG}$ was determined by assessing the severity of nausea and heartburn, and when they occurred; the frequency and amount of vomiting; the type (liquid or solid type) and amount of oral intake; urine ketone; electrolytes; and body weight. 
Heartburn was expressed as a percentage of the remaining symptoms, assuming $100 \%$ on the first day of hospitalization. It was checked every day. The time and degree to which she felt nausea were checked every day. The severity of nausea was scored as very severe (score 5), severe (score 4), moderate (score 3), mild (score 2 ), very mild (score 1 ), and none (score 0 ). The frequency and amount of vomiting were reported twice a day. Follow-up electrolytes were assessed in 2 to 7 days, for a total of 6 times during the admission. Urine ketone was also checked in 2 to 7 days, for a total of 3 times during admission. Body weight of the patient was checked every 7 days.

\section{Therapeutic interventions and progress of symptoms}

The patient received inpatient treatment from February 13, 2019 to March 5, 2019, totaling 3 weeks in the department of Korean Medicine Obstetrics \& Gynecology at the Korean medicine hospital. The patient received herbal medicine in its distilled form, acupuncture, electro-acupuncture, sticker needles, cupping, and moxibustion. In addition, hydration was administered under medical consultation to prevent dehydration due to the lack of oral intake. She was prescribed Diclectin, which she brought to the hospital, but since she felt that it was not working, she discontinued it herself on hospital day 3 .

Bosaeng-tang gagambang was administered in its distilled form, a total of 4 times during the patient's hospital stay, with no change of composition for any administration. To make distilled herbal medicine, we had to make herbal decoction first and made distillate by distilling the decoction. The prescription shown in table 1 is the composition of herbal medicine per pack. (Table 1) The herbs were boiled in 4.5 times of water of the distillate to be made, for about 2 hours. The herbs were removed, and decoction was moved into the distillation-extraction machine (utility model of Korea 0315785) and boiled with a cooling system for 1 to 2 hours.

She was prescribed a pack (100 cc per pack) after each meal, to a total of 3 packs a day; however, due to nausea, not all doses were

Table 1. Composition of Bosaeng-tang Gagambang, per Pack

\begin{tabular}{cccc}
\hline Composition & Dose $(\mathrm{g})$ & Composition & Dose $(\mathrm{g})$ \\
\hline Atractylodis Rhizoma Alba & 4 & Fraxini Cortex & 4 \\
Linderae Radix & 4 & Cyperi Rhizoma & 4 \\
Pinelliae Tuber & 2 & Poria Sclerotium & 2 \\
Ginseng Radix & 2 & Glycyrrhizae Radix et Rhizoma, Licorice \\
Angelicae Gigantis Radix & 2 & Paeoniae Radix Alba \\
Cnidii Rhizoma & 2 & Amomi Semen \\
Ammomi Fructus Rotundus & 2 & Platycodi Radix \\
Aurantii Fructus Immaturus & 1.5 & Perillae Folium \\
Phyllostachyos Caulis in Taeniam & 2 & Zingiberis Rhizoma Recens \\
Sepiae Endoconch & 1 & Scutellariae Radix \\
Liriopis seu Ophiopogonis Tuber & 2 & Crataegi Fructus & 2 \\
Magnoliae Cortex & 2 & \\
\hline
\end{tabular}


taken. Therefore, the patient continued to take Bosaeng-tang gagambang in small portions. Medication adherence was estimated by counting the number of packs, of the 3 she was prescribed, that she did not take. In the end, the patient took 50 packs in 21 days, which was about 2 packs of Bosaeng-tang gagambang per day.

The acupoints used were GV20, ST36, PC06, and SP04. Acupuncture was administered once or twice a day during admission, for 15 minutes each time using 0.20 x $30 \mathrm{~mm}$ stainless steel needles. Electro-acupuncture was performed using Careband (Piomed Co.), a device that applied electrical stimuli on the wrist, at PC06, for 30 minutes or more/day during hospitalization. Sticker needles were applied at ST36, PC06, and SP04, which were changed every day at $8 \mathrm{PM}$. Moxibustion was administered with electronic moxa twice a day on PC06 in the morning and CV12 and CV13 in the afternoon, each for 20 minutes. Cupping was applied following the bladder meridian on the patient's back every day at 8 PM. (Table 2)

The patient complained of very severe nausea (score 5) throughout the day on hospital day 1 . After 5 days of Korean medicine treatment, it improved to a moderate intensity (score 3) but continued to persist throughout the day. On day
10 of treatment, nausea appeared only after meals with a mild intensity (score 2). After 11 days, she felt very mild nausea (score 1) only after meals. From day 15 of treatment, there was no nausea (score 0 ) or very mild nausea immediately after eating (score 1), and there was no nausea before or after vomiting (Fig. 2). (Table 3)

In the afternoon on the first day of hospitalization, she vomited twice and there were 4 and 6 episodes of vomiting in the next two days, respectively. After 4 days of treatment, vomiting occurred 0 to 2 times a day, and vomiting occurred only once a day or not at all after hospital day 10, when nausea relieved to mild (score 2) (Fig. 2). However, the amount of vomiting per session increased from $25-50 \mathrm{cc}$ to $50-250$ cc with the increase in oral intake. (Table 3)

Heartburn began to decrease on day 5 of treatment, was reduced to $60 \%$ on day 7 , and to $50 \%$ on day 12 . After 15 days of treatment, heartburn was at $20 \%$, and after day 18 , it decreased to less than $10 \%$, at which point she did not feel discomfort by it (Fig. 2). (Table 3)

\section{Evaluation of improvement during Korean medicine treatment}

After Korean medicine therapy, the patient's

Table 2. Acupuncture and Moxibustion for the Treatment

\begin{tabular}{ll}
\hline \multicolumn{1}{c}{ Acupoints } & \multicolumn{1}{c}{ Acting } \\
\hline GV20, ST36, PC06, and SP04 & acupuncture, once or twice a day for 15 minutes \\
PC06 & electro-acupuncture using Careband, for 30 minutes or more/day \\
ST36, PC06, and SP04 & sticker needles, once day \\
PC06 & electronic moxa, once a day(morning) for 20 minutes \\
CV12 and CV13 & electronic moxa, once a day(afternoon) for 20 minutes \\
the bladder meridian on the patient's back & cupping, once a day for 5 minutes \\
\hline
\end{tabular}

124 http://dx.doi.org/10.13048/jkm.20051 

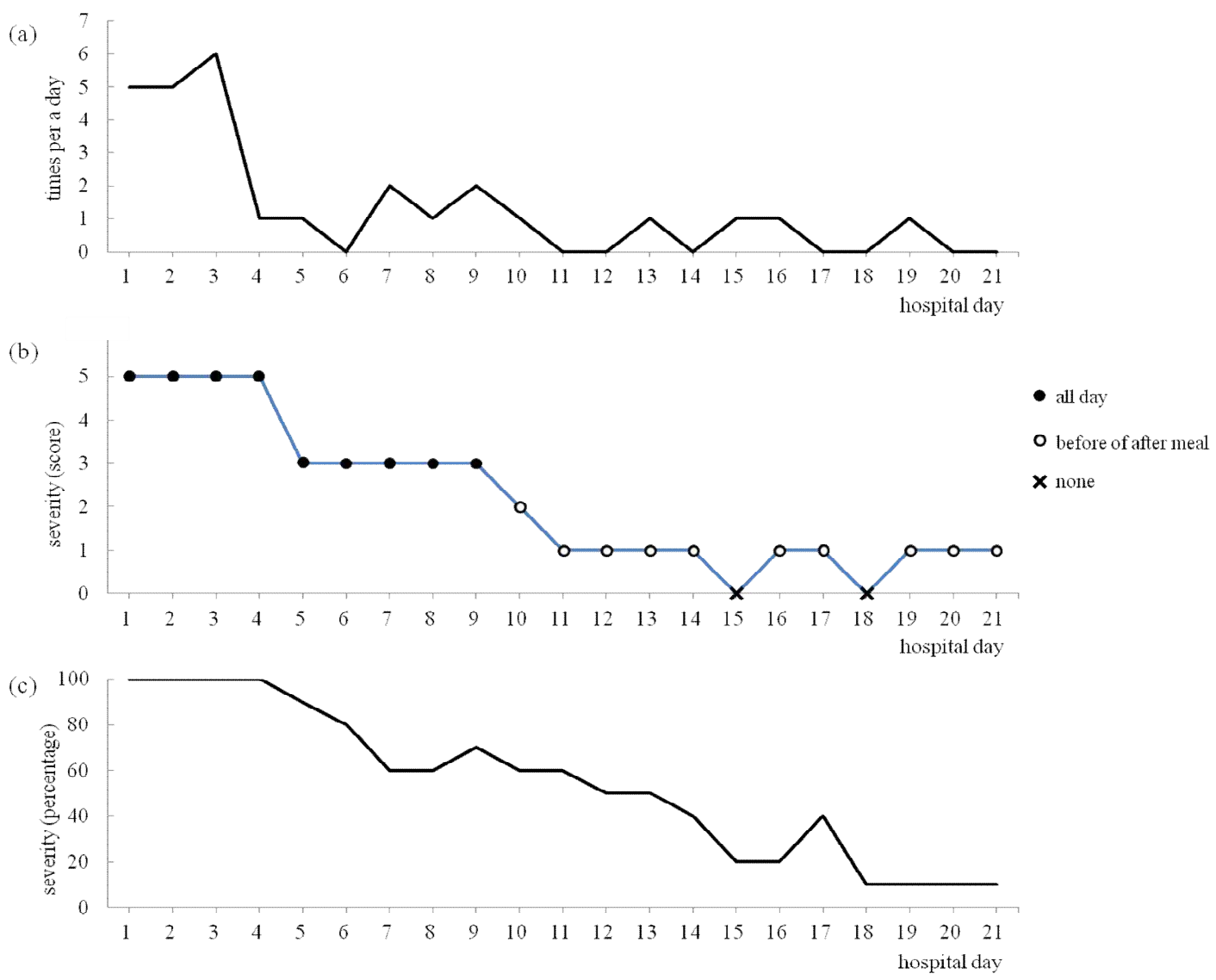

Fig. 2. Progress of main symptoms
(a) the frequency of vomiting per day
(b) the severity of nausea; very severe (score 5), severe (score 4), moderate (score 3), mild (score 2), very mild (score 1), and none (score 0)
(c) the severity of heart burn expressed as a percentage, assuming $100 \%$ on the first day of hospitalization

weight loss was suspended and the weight at discharge had increased by $1 \mathrm{~kg}(1.91 \%)$ compared to that at admission. Symptoms the patient complained were significantly improved after Korean medicine treatment. Serum sodium increased from $129 \mathrm{mmol} / \mathrm{L}$ to $134 \mathrm{mmol} / \mathrm{L}$, but it remained slightly below the normal limit. Serum potassium increased from $3.2 \mathrm{mmol} / \mathrm{L}$ to $3.3 \mathrm{mmol} / \mathrm{L}$ but had decreased to $2.9 \mathrm{mmol} / \mathrm{L}$ by discharge. Chloride remained normal throughout the hospital stay. On urinalysis, which was performed immediately after hospitalization, ketone, urobilinogen, and bilirubin were detected at $3+, 2+$, and $1+$, respectively. On urinalysis performed on day 6 and 16 for follow-up, all were negative and had improved normally. (Table 4)

\section{Safety of Korean medicine treatment}

No adverse effects were identified during and 
(662) Journal of Korean Medicine 2020;41(4) 
after Korean medicine therapy. Between discharge and giving birth, the patient recovered her pre-pregnancy weight. After discharge from the Korean medicine hospital, the patient did not need any treatment other than the Bosaeng-tang gagambang prescribed at the time of discharge. The patient gave birth to a healthy girl of normal weight through natural childbirth on August 14, 2019, at week 40 of pregnancy. At the time of birth, there was nothing unusual to note.

\section{Discussion and Conclusion}

Patients with HG have intense pain. The demand for treatment is high in both Korean medicine and conventional medicine. According to one study, about $0.8 \%$ of pregnant women hospitalized to conventional hospital obstetrics and gynecology departments are admitted for HG. ${ }^{3)}$ This is quite a high rate, considering that the incidence of $\mathrm{HG}$ is 0.5 to $2.0 \%$ of all pregnant women. In Korean medicine, $50.6 \%$ of herbal medicines used during pregnancy are for NVP or $\mathrm{HG}$, which accounts for the largest proportion of the reasons for taking herbal medicine during pregnancy. ${ }^{10)}$ Conventional hospital admissions for $\mathrm{HG}$ are most common in week 8 of pregnancy, at 1 per 1000 pregnant women, and the hospitalization rate decreases after that. In the current case, severe symptoms persisted until week 14 of pregnancy, when hospitalizations to treat $\mathrm{HG}$ at conventional hospitals are confirmed to be less than 0.5 per 1000 pregnant women. ${ }^{3)}$

Diclectin (doxylamine-pyridoxine), the drug this patient took for her $\mathrm{HG}$ before coming to the Korean medicine hospital, corresponds to the recommended level A treatment for NVP according to the American Society of Obstetrics and Gynecology guidelines. ${ }^{11)}$ It is reported that Diclectin has a few temporary side effects such as sleepiness, tiredness or drowsiness, but there was no any teratogenic adverse effect. ${ }^{12)}$ It was approved by the Korea Food and Drug Administration in September 2016 and is mostly prescribed to patients with NVP in Korea.

However, a randomized controlled trial in 2008 reported that the effect of Diclectin versus placebo in patients with NVP was not significant, and opinions on the effect were not unified. $^{13)}$ In addition, Diclectin's effect on NVP has been reported; however, its effect on HG has not yet been studied. The patient in this case did not have a positive response to Diclectin, so she discontinued it on hospital day 3 on her own.

Table 4. Progress of Serum Electrolytes and Urinalysis during Korean Medicine Therapy

\begin{tabular}{ccccccc}
\hline Date & Feb 14, 2019 & Feb 18, 2019 & Feb 22, 2019 & Feb 28, 2019 & Mar 2, 2019 & Mar 3, 2019 \\
(hospital day) & Day 2 & day 6 & Day 10 & Day 16 & Day 18 & Day 20 \\
\hline $\mathrm{Na} \mathrm{(mmol/L)}$ & $129 \boldsymbol{\nabla}$ & $134 \boldsymbol{\nabla}$ & $134 \boldsymbol{\nabla}$ & 135 & $134 \boldsymbol{\nabla}$ & $134 \boldsymbol{\nabla}$ \\
$\mathrm{K}(\mathrm{mmol} / \mathrm{L})$ & $3.2 \boldsymbol{\nabla}$ & $3.0 \boldsymbol{\nabla}$ & 3.3 & $2.9 \boldsymbol{\nabla}$ & 107 & 108 \\
$\mathrm{Cl}(\mathrm{mmol} / \mathrm{L})$ & 100 & 106 & 106 & - & & \\
Urobilinogen $^{*}$ & $2+$ & - & & - & \\
Ketone $^{*}$ & $3+$ & - & & - & \\
Bilirubin $^{*}$ & $1+$ & - & & & \\
\hline
\end{tabular}

* Detected on urinalysis 
Therefore, Korean medicine therapy can be considered as a treatment method for patients with HG, especially those who had no improvement after taking Diclectin.

The cause of HG in Korean medicine theory states that since menstruation suddenly stops in early pregnancy, qi and blood do not flow out and gather below to raise the fetus. At that time, the qi enlarges alone, flows backward, and invades the stomach. This induces failure of the stomach to descend qi, therefore if a pregnant woman primarily has a weakness of the spleen and stomach, the qi can invade the stomach easier. $^{14-15)}$ Therefore, the strategy of Korean medicine treatment is to regulate qi and harmonize the spleen and stomach, and to suppress vomiting by taking down qi. ${ }^{14)}$

Bosaeng-tang, which is traditionally used in Korean medicine for the treatment of NVP or HG with the weakness of spleen and stomach, was used by adding or subtracting herbs according to the patient's symptoms. ${ }^{14)}$ Among the added herbs, Pinelliae Rhizoma is classified as an herb that should be used with caution during pregnancy. ${ }^{16)}$ However, it is often used for NVP or HG within a safe dosage because it has a distinct effect. ${ }^{17)}$ In an animal study, Pinelliae Rhizoma has been reported to increase the rate of teratogenic effects only at very high doses, and there was no significant difference in implantation rate or number of miscarriages. ${ }^{18)}$ The most conservative conversion for the human body was about $12 \mathrm{~g}$, and $8 \mathrm{~g}$ of Pinelliae Rhizoma per day is well within the permitted range. ${ }^{17)}$ In this case, Pinelliae Rhizoma was administered at $4 \mathrm{~g}$ /day.

The patient complained of difficulty taking the herbal medicine due to its taste and smell, so
Bosaeng-tang gagambang was prescribed in its distilled form. The distilled form of herbal medicine is usually used in pediatrics since its bitter taste and smell leads many children to have difficulty taking it. ${ }^{19)}$ In clinical practice, distilled herbal medicine is often used in patients who are reluctant to take medicine due to NVP. Several case studies have shown the positive effect of Bosaeng-tang on NVP or HG. ${ }^{2,20-21)}$ However, no study has investigated the effectiveness of Korean medicine treatment including distilled herbal medications on NVP or HG. Previously published studies about distillation include a comparative analysis of the active ingredients of herbal medicine and its distilled form ${ }^{22)}$, animal studies on effect comparison $^{23-24)}$, and a case report about insomnia treated with distilled herbal medicine. ${ }^{25}$

Choi reported about gas chromatography (GC) of Samul-tang, Sakunja-tang, and their distillate. He used GC analysis to compare the active ingredients of herbal medicine and its distillate. Most of the active ingredients in Samul-tang and Sakunja-tang were moved into the distillate. The rest of the decoction after made distillate has few GC peaks, which means there are few active ingredients. Therefore, the report suggested the possibility that the distillate could be more effective than normal herbal medicines unless a cooler is used when making herbal medicines. ${ }^{22}$ However, few clinical studies investigated the effect of distilled form of herbal medicine. Further studies need to be undertaken to compare the effect of distillate to herbal medicine.

The acupoints, CV20, ST36, PC06 and SP04 used in this case are mainly used for the treatment of digestive symptoms. It was 
confirmed that PC06 has a significant effect on various types of stimuli such as acupressure by finger or band, acupuncture and electrical stimulation on NVP in various RCTs. ${ }^{26)}$ A systematic review about effect of acustimulation for NVP or HG reported that the following five acupoints were mainly used for acupuncture and moxibution; ST36, PC06, CV12, SP04, and SP06. ${ }^{27)}$ We continued to stimulate the acupoints using not only acupuncture, but also electro -acupuncture, moxibustion, stimulation with a sticker needle, and cupping.

The patient's dietary education was based on teaching that is commonly done for nausea and vomiting. The patient was instructed to consume a sports drink or water with salt and sugar at the first stage, soup at the second stage, and solids at the third stage. $^{28)}$ However, as her nausea decreased and appetite recovered, the patient ate foods that were difficult to digest, such as instant noodles or sausage. Although the dietary guidance on food intake was repeated, there were difficulties with managing the diet. Therefore, more systematic and repetitive dietary guidance and supervision may be needed when treating $\mathrm{HG}$ patients in clinical practice.

After treatment, the patient's electrolyte status, sodium and potassium, was found to be slightly lower than the normal levels. Since an oral diet was possible at the time of discharge, we focused on high-potassium and high-sodium diet education.

One limitation of this study was the absence of standardized evaluation indicators for the patient's quality of life (QOL) or degree of NVP. However, by investigating the patient's length and quality of sleep in addition to her NVP symptoms, it could be indirectly inferred that her quality of life had improved. (Table 3) The scale often used to assess QOL in patients complaining of NVP is the Motherisk Pregnancy -Unique Quantification of Emesis and Nausea scale (PUQE), which assesses QOL over a 12 hour period. ${ }^{29)}$ The scoring factors of PUQE include: how long the patient felt nauseated or sick to their stomach, the number of times they vomited, and the number of times they experienced retching or dry heaving without vomiting in the previous 12 hours. In this case, all the symptoms of the scale, except for the number of times they experienced retching or dry heaving, were recorded every day. During the first few days of admission, nausea and stomach pain were present throughout the day (over 7 hours), which would be a score of 5 . Frequency of vomiting per day was $4-5$, which would be a score of 4 . Even excluding retching or dry heaving, if added up, the score would be 9, which would be considered moderate. This would therefore be classified as severe considering the patient's condition at the time of admission.

This report is a single case, so there is a lack of supportive evidence to generalize the findings. However, the possibility of Korean medicine's positive therapeutic effect was confirmed for moderate or high $\mathrm{HG}$, which, for the case patient did not improve even after taking Diclectin and receiving inpatient treatment at obstetrics and gynecology hospitals. In previous studies, the treatment of NVP depended on the severity of symptoms in terms of QOL and fetal safety. ${ }^{30}$ The patient's symptoms showed remarkable improvement after Korean medicine treatment, and the patient successfully gave birth without any side effects. 
In summary, this report suggests that Korean medicine therapy with distilled herbal medicine may be an effective and safe option for $\mathrm{HG}$ patients, especially for who have no improvement with conventional treatment or refuse to take herbal medicine. Additionally, the results of the case could be the basis for further clinical studies on the subject.

\section{References}

1. Whitehead SA, Andrews PLR and Chamberlain GVP. Characterisation of nausea and vomiting in early pregnancy: a survey of 1000 women. J Obstet Gynaecol 1992;12:364-9.

2. Park JS and Lim EM. A case report of 1 patient complaining of hyperemesis gravidarium. Korean Obstet Gynecol. 2005;18(1):234-41.

3. DB Fell, L Dodds, KS Joseph, VM Allen and B Butler. Risk factors for hyperemesis gravidarum requiring hospital admission during pregnancy. Obstet Gynecol. 2006; 107(2Pt1):277-84.

4. ML Badell, SM Ramin and JA Smith. Treatment options for nausea and vomiting during pregnancy. Pharmacotherapy. 2006; 26(9):1273-87.

5. P Mazzotta, DE Stewart, G Koren and LA Magee. Factors associated with elective termination of pregnancy among Canadian and American women with nausea and vomiting of pregnancy. J Psychosom Obstet Gynaecol. 2001;22(1):7-12.

6. Poursharif B, Korst LM, Fejzo MS, MacGibbon KW, Romero R, and Goodwin TM. The psychosocial burden of illness of hyperemesis gravidarum. J Perinatol 2008; 28:176-81.
7. M.F.G. Verberg, D.J. Gillott, N.Al-Fardan and J.G.Grudzinskas. Hyperemesis gravidarum, a literature review. Hum. Reprod. Update. 2005;11(5):527-39.

8. Hwang BC and Kim SY. The effectiveness of antiemetics in hyperemesis gravidarum. J Korean Obstet Gynecol.. 2010;53(1):15-22.

9. Riley TR, Chinchilli VM, Shoemaker M and Koch K. Is nausea associated with chronic hepatitis C infection? Am J Gastroenterol 2001;96(12):3356-60.

10. Kim YG, Kim DC and Baek SH. A Clinical Analysis of 50 fetus that using Herbal Medication during Pregnancy. J Korean Obstet Gynecol. 2003;16(4):136-43.

11. American College of Obstetrics and Gynecology. ACOG (American College of Obstetrics and Gynecology) Practice Bulletin: nausea and vomiting of pregnancy. Obstet Gynecol. 2004; 103:803-14.

12. Atanackovic Z, Navioz Y, Mpretti M, and Koren G. The safety of higher than standard dose of doxylamine-pyridoxine (diclectin) for nausea and vomiting of pregnancy. J. Clin. Pharmacol. 2001;41:842-5.

13. $\mathrm{N}$ Persaud, $\mathrm{C}$ Meaney, $\mathrm{K}$ El-Emam, $\mathrm{R}$ Moineddin and $\mathrm{K}$ Thorpe. Doxylamine -pyridoxine for nausea and vomiting of pregnancy randomized placebo controlled trial: Prespecified analyses and reanalysis. PLOS one. 2018.13(1):e0189978.

14. The society of Korean medicine obstetrics and gynecology. Oriental obstetrics \& gynecology II. 1st ed. Seoul: Euiseongdang; 2012, p.493-9.

15. Lee C. Uihak-ipmun. Seoul: Daesung; 1984, p.1, 53, 320.

16. Kim DY. Guide training for the care of 
pregnant women who are targeted for the National happiness card (former Goun-mom card). The Association of Korean Medicine. 2015. Available from: URL: http://www.akom.org/Edu/EduAkomArticleNe ws? $\mathrm{id}=624822$ \&eduNewsType $=1 . \quad$ Accessed July 6, 2020.

17. Ahn IS, Kim DI, Choi MS and Kim SH. The analysis of delivery outcomes in cases of hyperemesis gravidarum patients medicated with Pinelliae Rhizoma - to establish a guideline in administration of Pinelliae Rhizoma. J Korean Obstet Gynecol. 2014; 27(3):94-103.

18. Yun YW. Evaluation for reproductive \& developmental toxicity and the study for mechanisms (II): TRC. Korea Food \& Drug Administration. 2004. Available from: URL: http://www.ndsl.kr/ndsl/commons/util/ndslOri ginalView.do?dbt=TRKO\&cn=TRKO201000 $016097 \& \mathrm{rn}=\& \mathrm{url}=\&$ page $\operatorname{Code}=\mathrm{PG} 18$. Accessed May 12, 2020.

19. Lee SJ, Lee SY and Yu SA. A Survey of Actual Guides for Children to Take the Oriental Medicine in the Oriental Clinics \& the Oriental Hospitals. J Pediatr Korean Med. 2013;27(3):12-9.

20. Kim JA and Kim DC. A case report of a triplets pregnant patient by in vitro fertilization with hyperemesis gravidarum. J Korean Obstet Gynecol. 2015;28(4):118-25.

21. Kim TH, Choi CM, Hong SE, Lee JJ and Yoo SK. Clinical study for the 20cases of the hyperemesis patients prescribed Kakambosengtang who have weakness of the spleen and stomach. J Korean Obstet Gynecol. 2002;15(1):128-38.

22. Choi SM. Study on the gas chromatography of Samul-tang, Sakunja-tang and their distillate. Korean J. Oriental Physiology \& Pathology. 2006;20(4):942-5.

23. Lee JW, Jang MH, Choi JS and Ahn TW. The effect of Yongyukjowitang distillate on the immune activity of spleen cells of aged rats. JSCM. 2013;25(3):218-32.

24. Lee $\mathrm{CH}$, Kim IH, Kim YE, Kim YJ, Hwang $\mathrm{JH}$ and $\mathrm{Yu} \mathrm{KW}$. Effect of steam distillates prepared from herbal medicines on immunostimulating activity. J Korean Soc Food Sci Nutr. 2004;33(4):626-32.

25. Shim SM, Kim TS and Koh YT. A case of distillation herbal medicine and counseling on insomnia. J of Oriental Neuropsychiatry. 2006;17(2):217-25.

26. Jang SW, Ahn IS, Choi MS and Kim DI Review on RCT research papers related nausea and vomiting in pregnancy Focusing on acupoint treatment -. J Korean Obstet Gynecol. 2013;26(2):138-50.

27. Van den Heuvel E, Goossens $M$, Vanderhaegen H, Sun HX and Buntinx F. Effect of acustimulation on nausea and vomiting and on hyperemesis in pregnancy: a systematic review of Western and Chinese literature. BMC Complement Altern Med. 2016;16:13.

28. Kenneth LK. Unexplained Nausea and Vomiting. Curr Treat Options Gastroenterol. 2000;3(4):303-313.

29. Koren G, Boskovic R, Hard M, Maltepe C, Navoiz $\mathrm{Y}$ and Einarson A. Motherisk-PUQE (pregnancy-unique quantification of emesis and nausea) scoring system for nausea and vomiting of pregnancy. Am. J. Obstet. Gynecol. 2002;186(5):228-31.

30. ML Badell, SM Ramin and JA Smith. 
(668) Journal of Korean Medicine 2020;41(4)

Treatment options for nausea and vomiting during pregnancy. pharmacotherapy. 2006;26(9): 1273-87.

\section{ORCID}

Hae-Won Kim https://orcid.org/0000-0002-0737-9338

Seon-Eun Baek https://orcid.org/0000-0002-8345-1864

Dong-Youl Yoo https://orcid.org/0000-0001-8750-9747

Jeong-Eun Yoo https://orcid.org/0000-0001-7087-1635

132 http://dx.doi.org/10.13048/jkm.20051 
Table 3. Progress of the Patient's Intake, Output, and Symptoms during Korean Medicine Therapy

\begin{tabular}{|c|c|c|c|c|c|c|c|c|c|c|c|c|c|c|c|c|c|c|c|c|c|c|}
\hline & Hospital Day & 1 & 2 & 3 & 4 & 5 & 6 & 7 & 8 & 9 & 10 & 11 & 12 & 13 & 14 & 15 & 16 & 17 & 18 & 19 & 20 & 21 \\
\hline \multirow{5}{*}{ Intake } & $\begin{array}{c}\text { Oral } \\
\text { (fluid) }\end{array}$ & $\begin{array}{l}\text { water, } \\
\text { juice, } \\
\mathrm{DB}^{\dagger}\end{array}$ & $\begin{array}{c}\text { water, } \\
\text { DB }\end{array}$ & $\begin{array}{c}\text { water, } \\
\text { sport } \\
\text { drinks, } \\
\text { DB }\end{array}$ & $\begin{array}{l}\text { water, } \\
\text { soup, } \\
\text { DB }\end{array}$ & $\begin{array}{c}\text { water, } \\
\text { sport } \\
\text { drinks, } \\
\text { DB }\end{array}$ & $\begin{array}{l}\text { water, } \\
\mathrm{DB}\end{array}$ & $\begin{array}{c}\text { water, } \\
\text { sport } \\
\text { drinks, } \\
\text { juice, } \\
\text { DB }\end{array}$ & $\begin{array}{c}\text { water, } \\
\text { sport } \\
\text { drinks, } \\
\text { DB }\end{array}$ & $\begin{array}{c}\text { water, } \\
\text { sport } \\
\text { drinks, } \\
\text { juice, } \\
\text { DB }\end{array}$ & $\begin{array}{c}\text { water, } \\
\text { sport } \\
\text { drinks, } \\
\text { DB }\end{array}$ & $\begin{array}{c}\text { water, } \\
\text { sport } \\
\text { drinks, } \\
\text { DB }\end{array}$ & $\begin{array}{c}\text { water, } \\
\text { sport } \\
\text { drinks, } \\
\text { juice, } \\
\text { DB }\end{array}$ & $\begin{array}{c}\text { water, } \\
\text { sport } \\
\text { drinks, } \\
\text { soup, } \\
\text { DB }\end{array}$ & $\begin{array}{c}\text { water, } \\
\text { sport } \\
\text { drinks, } \\
\text { DB }\end{array}$ & $\begin{array}{c}\text { water, } \\
\text { sport } \\
\text { drinks, } \\
\text { juice, } \\
\text { DB }\end{array}$ & $\begin{array}{c}\text { water, } \\
\text { sport } \\
\text { drinks, } \\
\text { DB }\end{array}$ & $\begin{array}{l}\text { water, } \\
\text { sport } \\
\text { drinks, } \\
\text { DB }\end{array}$ & $\begin{array}{c}\text { water, } \\
\text { sport } \\
\text { drinks, } \\
\text { DB }\end{array}$ & $\begin{array}{l}\text { water, } \\
\text { sport } \\
\text { drinks, } \\
\text { DB }\end{array}$ & $\begin{array}{c}\text { water, } \\
\text { sport } \\
\text { drinks, } \\
\text { DB }\end{array}$ & $\begin{array}{c}\text { water, } \\
\text { DB }\end{array}$ \\
\hline & $\begin{array}{c}\text { Oral } \\
\text { (liquid diet) }\end{array}$ & & & $\begin{array}{l}\text { rice } \\
\text { gruel }\end{array}$ & & $\begin{array}{l}\text { rice } \\
\text { gruel }\end{array}$ & & $\begin{array}{l}\text { rice } \\
\text { gruel }\end{array}$ & & $\begin{array}{c}\text { thin rice } \\
\text { gruel }\end{array}$ & $\begin{array}{l}\text { thin rice } \\
\text { gruel }\end{array}$ & $\begin{array}{l}\text { thin rice } \\
\text { gruel }\end{array}$ & & & & & $\begin{array}{l}\text { Cheong } \\
\text { gukjang }\end{array}$ & & & & & \\
\hline & $\begin{array}{c}\text { Oral } \\
\text { (solid diet) }\end{array}$ & & $\begin{array}{c}2 \\
\text { cherries } \\
1 \text { tomato }\end{array}$ & & $\begin{array}{l}\text { rice, } \\
\text { ice-crea } \\
\text { m }\end{array}$ & $\begin{array}{l}\text { instant } \\
\text { noodles }\end{array}$ & $\begin{array}{l}\text { rice, } \\
\text { instant } \\
\text { noodles }\end{array}$ & & & & & $\begin{array}{l}\text { curry } \\
\text { rice }\end{array}$ & $\begin{array}{c}\text { pork } \\
\text { trotters }\end{array}$ & banana & $\begin{array}{c}\text { banana, } \\
\text { Galbi-ta } \\
\text { ng }\end{array}$ & $\begin{array}{l}\text { noodles, } \\
\text { Sundae }\end{array}$ & & $\begin{array}{l}\text { curry } \\
\text { and rice }\end{array}$ & $\begin{array}{c}\text { normal } \\
\text { meal }\end{array}$ & $\begin{array}{c}\text { normal } \\
\text { meal }\end{array}$ & $\begin{array}{l}\text { noodles, } \\
\text { sausage, } \\
\text { peach, } \\
\text { Gimbap }\end{array}$ & \\
\hline & $\begin{array}{c}\text { Oral } \\
\text { (total volume) }\end{array}$ & 150 & 400 & 910 & 1140 & 1160 & 940 & 1010 & 50 & 450 & 650 & 890 & 700 & 620 & 740 & 1210 & 890 & 1040 & 840 & 960 & 650 & 120 \\
\hline & $\begin{array}{c}\text { Parenteral } \\
\text { (volume) }\end{array}$ & 100 & 1300 & 900 & 1400 & 1000 & 800 & 1100 & 900 & 1100 & 1000 & 1200 & 800 & 1000 & 900 & 1000 & 1100 & 700 & 1300 & 1100 & 900 & 300 \\
\hline \multirow{4}{*}{ Output } & Urine & 200 & 750 & 1000 & 1600 & 1400 & 1450 & 1400 & 800 & 1000 & 1000 & 1200 & 1100 & 1000 & 1500 & 1700 & 1500 & 1700 & 1200 & 1300 & 1300 & 600 \\
\hline & $\begin{array}{l}\text { Vomiting } \\
\text { (times) }\end{array}$ & 5 & 5 & 6 & 1 & 1 & 0 & 2 & 1 & 2 & 1 & 0 & 0 & 1 & 0 & 1 & 1 & 0 & 0 & 1 & 0 & 0 \\
\hline & $\begin{array}{l}\text { Vomiting } \\
\text { (volume) }\end{array}$ & 50 & 100 & 200 & 50 & 100 & 0 & 500 & 100 & 100 & 70 & 0 & 0 & 50 & 0 & 50 & 200 & 0 & 0 & 150 & 0 & 0 \\
\hline & Stool & & & & 1 & 1 & 1 & 1 & & & & & & 3 & 2 & & 1 & & 1 & & & \\
\hline \multirow{2}{*}{ Nausea } & Time & all day & all day & all day & all day & all day & all day & $\begin{array}{l}\text { after } \\
\text { meal }\end{array}$ & all day & all day & $\begin{array}{l}\text { after } \\
\text { meal }\end{array}$ & $\begin{array}{l}\text { after } \\
\text { meal }\end{array}$ & $\begin{array}{l}\text { after } \\
\text { meal }\end{array}$ & $\begin{array}{l}\text { after } \\
\text { meal }\end{array}$ & $\begin{array}{l}\text { after } \\
\text { meal }\end{array}$ & none & $\begin{array}{l}\text { after } \\
\text { meal }\end{array}$ & $\begin{array}{l}\text { after } \\
\text { meal }\end{array}$ & none & $\begin{array}{c}\text { before } \\
\text { meal }\end{array}$ & $\begin{array}{l}\text { after } \\
\text { meal }\end{array}$ & $\begin{array}{l}\text { after } \\
\text { meal }\end{array}$ \\
\hline & $\begin{array}{l}\text { Severity } \\
\text { (score) }\end{array}$ & 5 & 5 & 5 & 5 & 3 & 3 & 3 & 3 & 3 & 2 & 1 & 1 & 1 & 1 & 0 & 1 & 1 & 0 & 1 & 1 & 1 \\
\hline Heart burn & $\begin{array}{c}\text { Severity } \\
\text { (percentage) }\end{array}$ & 100 & 100 & 100 & 100 & 90 & 80 & 60 & 60 & 70 & 60 & 60 & 50 & 50 & 40 & 20 & 20 & 40 & 10 & 10 & 10 & 10 \\
\hline Insomnia & $\begin{array}{l}\text { Sleeping time } \\
\text { and quality }\end{array}$ & $\begin{array}{c}4.5 \text { hours } \\
\text { poor }\end{array}$ & $\begin{array}{c}4.5 \text { hours } \\
\text { poor }\end{array}$ & & & $\begin{array}{c}7 \text { hours } \\
\text { good }\end{array}$ & & & & & $\begin{array}{c}8 \text { hours } \\
\text { good }\end{array}$ & & $\begin{array}{c}7 \text { hours } \\
\text { poor }\end{array}$ & $\begin{array}{c}6 \text { hours } \\
\text { poor }\end{array}$ & & $\begin{array}{l}9 \text { hours } \\
\text { good }\end{array}$ & $\begin{array}{c}9 \text { hours } \\
\text { good }\end{array}$ & & $\begin{array}{c}9 \text { hours } \\
\text { good }\end{array}$ & $\begin{array}{c}9 \text { hours } \\
\text { good }\end{array}$ & $\begin{array}{c}8 \text { hours } \\
\text { good }\end{array}$ & \\
\hline
\end{tabular}

* Percentage of symptom remaining

DB: distillate of Bosaeng-tang gagambang 